\title{
OS USOS DA TECNOLOGIA COMO MECANISMO BIOPOLÍTICO ${ }^{1}$
}

\author{
Mariana Rocha Bernardi ${ }^{2}$ \\ Simone Côrte Real Barbieri ${ }^{3}$
}

\begin{abstract}
RESUMO
O presente artigo busca problematizar os impactos dos usos da tecnologia no que se refere ao desenvolvimento social. Ou seja, compreender quais as consequências das chamadas máquinas inteligentes e das ferramentas de informação e gestão utilizadas para a administração das relações e das produções na contemporaneidade. Esses usos serão tematizados a partir de Feenberg pela discussão do envolvimento tecnológico com o mundo e da mudança de nossa perspectiva de abordagem, entendimento e relacionamento com a realidade em função desse novo modo; e a partir de Foucault, discutindo os usos da tecnologia como parte de um fazer político orientado para o atendimento das demandas mercadológicas, que repercute em controle subjetivo e não administração dos problemas da realidade. Como resultado do artigo se apresenta a necessidade da aplicação da perspectiva ética como condição para qualificação dos usos da tecnologia e seu o comprometimento com os processos de emancipação humana.
\end{abstract}

Palavras-Chave: Tecnologia; Biopolítica; Ética; Máquinas Inteligentes.

\section{THE USES OF TECHNOLOGY AS A BIOPOLITICAL MECHANISM}

\begin{abstract}
The present article aims to problematize the impacts of technology uses in social development. In other words, it intends to comprehend which consequences may result from intelligent machines and management tools information used for the administration of relations and productions in contemporary times. These uses will be themed from Feenberg by discussing technological involvement with the world and changing our perspective of approach, understanding and relationship with reality due to this new way; and from Foucault, discussing the uses of technology as part of a political activity oriented towards meeting market demands, which has repercussions on subjective control and non-management of the problems of reality. As a result of the article, there is a need to apply the ethical perspective as a condition for qualifying the uses of technology and its commitment to human emancipation processes.
\end{abstract}

Keywords: Technology; Biopolitics; Ethics; Intelligent machines.

1 O presente trabalho foi realizado com apoio da Coordenação de Aperfeiçoamento de Pessoal de Nível Superior Brasil (CAPES) - Código de Financiamento 001, nos termos da Portaria 206, de 04 de setembro de 2018.

2 Doutoranda em Filosofia pelo Programa de Pós-graduação em Filosofia da Universidade de Caxias do Sul. Bolsista PROSUC/CAPES. Mestre em Filosofia pelo mesmo programa. Linha de pesquisa: Ética aplicada. Email: mrocha2@ucs.br. http://orcid.org/0000-0002-5805-9588

3 Doutora em Educação pelo Programa de Pós-graduação em Educação da Universidade de Caxias do Sul. Mestre em Filosofia pelo Programa de Pós-graduação em Filosofia da PUC/RS. Professora da Universidade de Caxias do Sul vinculada à área de Humanidades. Linhas de pesquisa: Ética, epistemologia, educação, biopolítica. E-mail: scrbarbi@ucs.br. http://orcid.org/0000-0002-4845-7603 


\section{CONSIDERAÇÕES INICIAIS}

O cotidiano mundial na contemporaneidade é do império da tecnologia, em que pese mais de 300 milhões de pessoas ainda "amarguem" em estado de desnutrição e morram de fome. Num quadro que mescla o caótico da necessidade por alimento com a engenhosidade de máquinas cada vez mais "inteligentes", somos impelidos a questionar se o progresso intelectual vale o retrocesso moral. Vivemos em um mundo onde se desenvolvem robôs para limpar casas e emitir sentenças, além de já trabalharmos com a nanotecnologia ${ }^{4}$ em diferentes áreas de aplicação, entretanto o acesso ao desenvolvimento da tecnociência não chega à maioria da população mundial ${ }^{5}$, e destoa em muito da forma como gerimos as necessidades humanas mais básicas.

A grande promessa para uma melhor gestão de problemas sociais, tais como a desigualdade, a falta de acesso à alimentação e recursos de saneamento, o acesso ao emprego, entre outros, estaria justamente no uso dessas ferramentas tecnológicas, e entre elas, a inteligência artificial. A evolução das tecnologias nos posicionou em uma conjuntura em que o não uso delas nos torna obsoletos, ao mesmo tempo em que seu uso indiscriminado gera uma série de impactos negativos a grande parte das pessoas inseridas nas mais diversas sociedades. Assim, apesar das benesses trazidas pelas tecnologias, dos inúmeros avanços ocasionados por elas, da rapidez com que se processam informações, algumas questões, como a preocupação com o humano e as relações intersubjetivas, parecem estar ficando em segundo plano.

O objetivo do presente artigo é, pois, possibilitar uma reflexão sobre os usos das tecnologias, em especial a inteligência artificial, e alguns de seus impactos na sociedade. Busca-se compreender como se efetiva a utilização das tecnologias, especialmente das máquinas inteligentes, e as consequências desses usos para o desenvolvimento social. Para esta reflexão apresenta-se primeiramente, a discussão sobre os possíveis usos da tecnologia e suas reverberações nas relações humanas com o meio e com os outros. Essa discussão é feita a partir de Feenberg e

\footnotetext{
4 "A nanotecnologia é o estudo de manipulação da matéria em escala atômica e molecular e incluí o desenvolvimento de materiais que está associada a diversas áreas como a medicina, eletrônica, ciência da computação, física, química, biologia e engenharia dos materiais entre outras.". Disponível em http://www.cetene.gov.br/index.php/area-de-atuacao/nanotecnologia/.

5 Disponível em http://agenciabrasil.ebc.com.br/internacional/noticia/2018-12/mais-da-metade-da-populacaomundial-esta-comectada-internet-diz-onu. Acesso em 09 de agosto de 2019, às 14 horas e 33 minutos.
}

Qovista Dialectus

Ano 10 n. 23

Maio - Agosto 2021

p. $251-266$ 
Foucault, investigando as particularidades dos usos da tecnologia no que se refere as possibilidades de controle e captura advindas da aplicação dos mecanismos de inteligência artificial, sejam elas intencionais ou resultantes dos processos ainda em desenvolvimento. Seguida pela problematização dos usos da tecnologia como parte de um fazer político e mercadológico com interesses definidos pelas perspectivas da biopolítica. Por fim se afirma a necessidade de uma abordagem ética como caminho para uma qualificação da aplicação tecnológica e como critério norteador para seus usos como ferramenta de informação, gestão e administração dos recursos e das condições de vida humanas.

\section{REFLEXÕES ACERCA DA TECNOCIÊNCIA: TECNOLOGIA E INTELIGÊNCIA ARTIFICIAL}

Nos negócios, a implementação de softwares dotados de inteligência artificial possibilitou a análise de dados de mercado, como comportamentos de clientes e potenciais clientes, preços de produtos e serviços, incidência de tributação e estratégias de venda, apenas para citar alguns exemplos da aplicação dessa tecnologia. O desenvolvimento da inteligência artificial também dotou de capacidade de convergência de informações as ferramentas de busca da internet, as redes sociais ${ }^{6}$, e alguns aplicativos de smartphones ${ }^{7}$. Ferramentas como o Google, Netflix, Facebook e Instagram, são dotadas de algoritmos capazes de aprender com a navegação dos usuários, que transmitem informações sobre preferências e necessidades diariamente na rede mundial de computadores.

É inegável que uma capacidade maior de captação e processamento de informações auxilia na rotina de trabalho e até mesmo no lazer. Atualmente não é mais necessário buscar informações e documentos relativos a um cliente bancário, ou ir a uma loja fazer compras ou

6 Estruturas concebidas a partir de programações de computador e que, com o auxílio da internet, possibilitam a conexão entre pessoas que possuem algum elemento em comum, permitindo a interação simultânea entre essas pessoas, em qualquer lugar do mundo.

7 Telefones celulares inteligentes. Trata-se de telefones portáteis, de uso individual, com acesso à internet e dotado de diversas ferramentas e aplicativos cujo objetivo é auxiliar o portador a realizar tarefas diárias com maior eficácia. Entre algumas de suas aplicações estão o acesso às redes sociais, a execução de cálculos diversos, por meio de diferentes programas de cálculo, acesso e movimentação de conta bancária, jogos, acesso à vídeos e à grande mídia, a qualquer momento, dependendo apenas da velocidade de conexão da internet.

\begin{tabular}{|c|c|c|c|c|}
\hline Qevista Dialectus & Ano 10 & n. 23 & Maio - Agosto 2021 & p. $251-266$ \\
\hline
\end{tabular}


perguntar a um crítico de cinema sobre os melhores filmes e séries. Softwares dotados de inteligência artificial buscam elementos relacionados a clientes em segundos e sugerem a eles os melhores serviços; sites como a Amazon aprendem com as preferências de compra do cliente e sugerem produtos, além de organizar toda a aquisição de insumos, até a efetivação do pagamento pelo consumidor; plataformas como o Netflix indicam as melhores séries e filmes a partir das preferências outrora inseridas pelos usuários e capturadas pelas máquinas.

A tecnologia, compreendida como indispensável ao desenvolvimento humano, pressupõe o uso de técnicas e instrumentos que visam à resolução de problemas, sendo sua acessibilidade universal. No texto A Teoria Crítica, Feenberg (2010) problematiza sobre a autonomia da técnica, ou seja, se o fenômeno tecnológico determina o modo de existência humano? A partir dessa obra é possível afirmar que a tecnologia não é neutra: os instrumentos dão forma ao nosso modo de vida. "Como fazemos as coisas determina quem somos e o que somos. O desenvolvimento tecnológico transforma o que é ser humano" (FEENBERG, 2010, p, 207). De maneira que é preciso compreender a produção da tecnologia e suas possibilidades de aplicação de forma específica.

A tecnologia é indispensável ao ser humano, tanto pelo implemento da produção das máquinas e dos recursos, quanto pelas mudanças nos nossos modos de existir e de relacionamento com a realidade e com os outros viabilizados por esse implemento. A tecnologia é especialmente identificada com a construção e uso das máquinas, em diversos segmentos. As máquinas, por sua vez, podem ser definidas como objetos materiais crescentemente complexos que envolvem diferentes peças, engendradas de maneiras específicas para produzir ou reproduzir certas finalidades, objetivadas pelo ser humano. Andrew Feenberg (2015, p. 54) explica em seus estudos que existe uma diferença entre o que ele chama de atores e agentes sociais, e que é determinada pela questão econômica, especialmente no que tange ao uso de tecnologia. Conforme sua análise,

o conceito de "enviesamento formal" [formal bias] para compreender como um sistema racional pode ter consequências discriminatórias. Este é um ponto difícil porque normalmente pensamos do enviesamento como o resultado de emoções irracionais, ideias falsas, e privilégios injustificados. A teoria do enviesamento da tecnologia depende de uma ideia que encontrei originalmente em Marx, mas que refinei com conceitos extraídos dos estudos sobre ciência e tecnologia. A crítica de Marx à economia política mostrou que a racionalidade do mercado produzia desigualdades de classe, apesar da sua aparência de equidade e de reciprocidade. Os estudos de ciência e tecnologia podem ser interpretados

\begin{tabular}{|l|l|l|l|l|}
\hline Revista Dialectus & Ano 10 & n. 23 & Maio - Agosto 2021 & p. 251 - 266 \\
\hline
\end{tabular}


como estendendo uma ideia semelhante à racionalidade técnica. Tal como os mercados, os dispositivos servem a todos igualmente, mas o seu projeto está acomodado aos interesses e visões dos atores específicos, por vezes à custa de outros atores com menos poder.

Assim, o ser humano passou a alterar ou regular algumas de suas mais importantes dinâmicas sociais e de mercado (implantação dos algoritmos em redes sociais e em empresas) a partir do desenvolvimento dessas novas ferramentas tecnológicas. Não é por acaso que a programação de cada inteligência artificial tendencialmente seja orientada por interesses difusos, de certos grupos ou categorias econômicas ou do próprio Estado, que se aproveita do progresso técnico para atualizar e renovar os seus meios de produção, distribuição e consumo, a fim de manter a estrutura de um sistema organizado entre aqueles que ditam ou influenciam regras, e os que as obedecem. Essa explicação se pode verificar pela análise de Foucault a respeito da governamentalidade (1984, p. 164), que explica que as estruturas definem "o problema de como ser governado, por quem, até que ponto, com qual objetivo, com que método etc.". Assim, observadas as organizações e as formas de implementação das inteligências artificiais, pode-se concluir que essa tecnologia pode ser desenvolvida e implementada conforme certos parâmetros previamente definidos, e que estejam eivados de vícios ou interesses específicos.

Ainda que Foucault não tenha como objeto de seus estudos as máquinas inteligentes, o sistema observado por ele cria, de tempos em tempos, novas formas de controle, para organização social (por meio do exercício de poder). Para ele "a razão de Estado é precisamente uma prática, ou antes, uma racionalização de uma prática que vai se situar entre um Estado apresentado como dado e um Estado apresentado como a construir e a edificar.” (FOUCAULT, 2008, p. 14). Roberto Machado, na explicação que faz da genealogia do poder, de Michel Foucault, na introdução à obra deste, Microfísica do poder, refere a "existência de formas de exercício de poder diferentes do Estado, a ele articuladas de maneiras variadas e que são indispensáveis inclusive a sua sustentação e atuação eficaz." (MACHADO, 2006, p. 11). O que ele chama de biopoder, termo que designa essa forma de atuação biopolítica, a saber:

Em 1978, no curso intitulado Segurança, território, população, Foucault estabelece como fio condutor de suas análises o estudo do biopoder, definindo-o como "o conjunto dos mecanismos pelos quais aquilo que, na espécie humana, constitui suas características

\begin{tabular}{|l|l|l|l|l|}
\hline Revista Dialectus & Ano 10 & n. 23 & Maio - Agosto 2021 & p. 251 - 266 \\
\hline
\end{tabular}


biológicas fundamentais, vai poder entrar numa política, numa estratégia política, numa estratégia geral do poder". (Foucault, 2008a, p. 03) ${ }^{8}$

A inteligência artificial tem sido usada para obtenção e manipulação de dados, a fim de exercer influência sobre as escolhas dos indivíduos, significa dizer, trata-se de um novo meio pelo qual alguns indivíduos podem exercer certas influências sobre outros, de modo a fixar uma relação de poder. Essa orientação pode ser visualizada por meio das diversas formas de interação entre as pessoas e os dispositivos de inteligência artificial, seja por meio do mercado, seja pelas novas formas de transação, que são ofertadas por meio de plataformas digitais, na virtualização dos negócios.

Impende esclarecer aqui que nas sociedades capitalistas de mercado, organizadas democraticamente, os órgãos de controle no sentido próprio da palavra são estatais - as diferentes polícias, o ministério público, o poder judiciário e os sistemas de administração penitenciária fazem pouco uso das preferências individuais. Destaca-se, ainda, neste ponto, certa ambiguidade da inteligência artificial: conquanto seja paulatinamente usada ao bel prazer do mercado, determinado por interesses difusos, porém concentrados em pequenos grupos ou numa minoria, quando da sua introdução nas vidas das pessoas, mormente por meio das redes sociais, o desejo pelo seu uso restou inequívoco.

Trata-se do que se poderia chamar de "retroalimentação": a máquina aprende com as informações que lhe são inseridas e a partir da forma como seus algoritmos são programados, e retorna essas mesmas informações de maneira otimizada na forma de solução de problemas, indicação ou orientação de tomadas de decisões aos usuários, seja no que irão comprar, o que irão assistir ou em quem vão votar?

Cathy O’Neil, cientista matemática americana, na obra Weapons of math destruction, chama a atenção para a forma como os algoritmos de inteligência artificial tem impactado a

8 Citado por CAMILO, Juliana Aparecida de Oliveira e FURTADO, Rafael Nogueira, no artigo $O$ conceito de biopoder no pensamento de Michel Foucault. Rev. Subjetividades, vol.16 n. 3 - Fortaleza / Dez 2016. Disponível em http://pepsic.bvsalud.org/scielo.php?script=sci arttext\&pid=\$2359-07692016000300003. Acesso em 13 de julho de 2019, às 15 horas e 47 minutos.

9 Quanto a esse respeito, vide matéria no link https://www.bbc.com/portuguese/geral-37961917. Na época das eleições americanas para presidência, em 2016, a citada notícia explicou da seguinte forma a atuação do algoritmo de inteligência artificial da rede social facebook: “(...) o algoritmo do feed de notícias [da rede social] veicula o que "pensa" ser a sua opinião e a de seus amigos e certamente não checa fatos. Um exemplo é que, durante a campanha

\begin{tabular}{|l|l|l|l|l|}
\hline Qevista Qialectus & Ano 10 & n. 23 & Maio - Agosto 2021 & p. 251 - 266 \\
\hline
\end{tabular}


sociedade humana, uma vez que alguns softwares têm criado padrões de escolha que tendem a reproduzir preconceitos e deixar de lado elementos subjetivos que apenas uma avaliação humana seria capaz de fazer.

Num dos exemplos citados pela autora, há referência a uma ferramenta de inteligência artificial que avaliou os professores de uma determinada escola e acabou por orientar a demissão de boa parte deles, ainda que muitos gozassem de boa reputação junto à comunidade escolar da região citada na obra. Observa-se, portanto, que algumas das consequências imediatas é o favorecimento ou desfavorecimento de pessoas que possuam determinadas características, como poder aquisitivo, grupo a que pertença, sexo e cor da pele, a influenciar uma pontuação maior ou menor pelo algoritmo que analisa e compila diversas informações.

Em 2014, uma ferramenta de inteligência artificial foi implementada na empresa Amazon, para auxiliar na contratação de funcionários, por meio da atribuição de pontuação através da inserção de "quantidade de estrelas", para determinar a maior ou menor propensão a determinado cargo, conforme o número de estrelas atribuído. O resultado foi que a citada ferramenta excluía os candidatos femininos, com base nos currículos existentes na base de dados dos últimos 10 anos da empresa ${ }^{10}$. Observando esse caso pontual, se as programações das máquinas inteligentes não observarem esse comportamento que ainda subsiste em sociedade, da diferença atribuída entre o trabalho do homem e da mulher, por exemplo, e potencializado pelas máquinas, haverá problemas em todas as áreas onde a inteligência artificial for implementada.

Se já existe diferença entre o trabalho de um homem e de uma mulher e a máquina estiver acima da produção do homem, a mulher não terá somente a figura masculina como concorrente no mercado, mas também a máquina, rebaixando-se ainda mais sua condição. Imaginese a mesma situação ocorrendo com deficientes, outras raças e demais minorias, já historicamente segregadas. Ora, é claro que não se pode olvidar que a programação da inteligência artificial está

presidencial americana, histórias acusando Hillary de assassinato ou que "revelavam que o presidente Barack Obama é muçulmano" apareceram nas páginas de pessoas com tendência de apoio a Trump. Também ocorreu o contrário. Uma falsa declaração supostamente feita pelo bilionário em 1998, em que ele dizia que seria simples ser candidato pelo Partido Republicano "porque seus eleitores são burros", continua circulando na rede social graças ao compartilhamento de americanos que não gostam de Trump.".

10 Disponível em https://meiobit.com/391571/ferramenta-de-recrutamento-amazon-ai-discriminava-mulheres/. Matéria original: https://www.reuters.com/article/us-amazon-com-jobs-automation-insight/amazon-scraps-secretai-recruiting-tool-that-showed-bias-against-women-idUSKCN1MK08G.

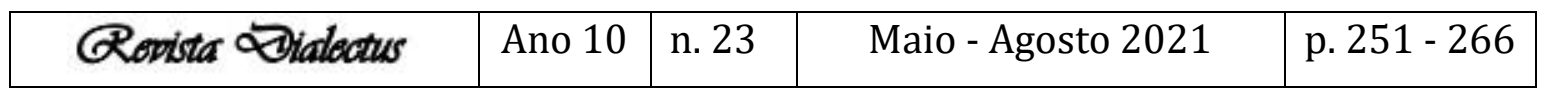


sujeita aos equívocos do humano. Não se trata, portanto, de lançar críticas à tecnologia da inteligência artificial, mas sim de criticar a forma como ela é desenvolvida e implementada em alguns segmentos, e que podem resultar em impactos negativos para a maioria das pessoas, ou ao menos, grande parte delas. ${ }^{11}$

\section{ALGORITMOS E A SUPERVISÃO HUMANA}

A inteligência artificial é estruturada para se assemelhar à forma humana de pensar ou raciocinar. Seu funcionamento se efetiva por meio da programação de algoritmos, que usam informações recebidas e processadas, seguindo determinadas instruções. Quando encontra padrões entre as informações e instruções recebidas, passa a conectá-las, a fim de realizar determinada $a c ̧ a ̃ o$ (pode ser um cálculo, um texto, uma rotina de trabalho).

A máquina, em que pese não ter consciência, intelecto ou alma para apreender algo, tem condições de tecer relações entre os elementos que estruturam sua programação, sendo mais ou menos flexível a forma como dará um output, dependendo do modo como foi estruturado o algoritmo que regula seu funcionamento. Ela forma padrões, por força bruta de processamento, mas tendo como objetivo alcançar os padrões da sutileza da mente humana: "O campo do machine learning (aprendizado de máquina) se ocupa da questão de como construir programas de computador que automaticamente melhorem com a experiência" (MITCHELL, 1997, p. Xv do prefácio). Conforme explicação de Juan Durán (2018, p. 08),

Muitas de nossas atividades diárias podem ser descritas como um simples conjunto de
regras que repetimos sistematicamente. Acordamos a certa hora do dia, escovamos os
dentes, tomamos banho e saímos para o trabalho. É claro que modificamos nossa rotina,
mas apenas o suficiente para torná-la de alguma forma mais vantajosa: eles nos dão mais
tempo na cama, minimizam a distância entre paradas ou satisfazem todos em casa. De
certa forma, essas rotinas diárias capturam o que chamamos de algoritmo no sentido de
que, para ambos os casos (por exemplo, na rotina e no algoritmo), há uma repetição do
mesmo conjunto de ações repetidas vezes. (...) Portanto, na minha opinião, a noção de

11 Conforme pesquisa do artigo intitulado Mediation Challenges and Socio-Technical Gaps for Explainable Deep Learning Applications, foram entrevistados diversos especialistas desenvolvedores de modelos de aprendizado de máquina. Foi constatado que a maioria deles não considera que seja responsabilidade deles lidar com os problemas de viés ou implicações relacionadas ao uso inadequado da tecnologia. Ou seja, eles não se engajam em considerações a respeito do significado social destas tecnologias que eles desenvolvem. Muitos acreditam que a responsabilidade é de um terceiro (mediador), cujo papel ainda não está definido nas atuais linhas de produção desta tecnologia. Disponível em https://arxiv.org/ftp/arxiv/papers/1907/1907.07178.pdf

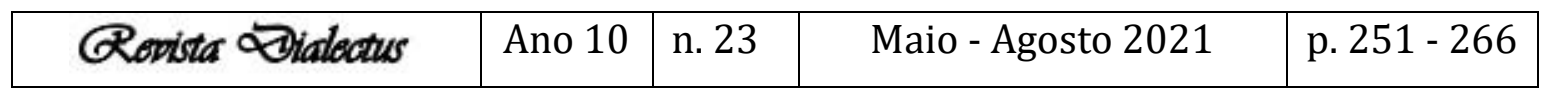


algoritmo repousa na ideia de que é parte de um procedimento sistemático, formal e finito. $^{12}$

Os padrões de comportamento humano e as preferências de quem encomenda e/ou programa a inteligência artificial acabam influenciando os resultados que, em que pese otimizados, restam eivados de problemas que pretender-se-iam eliminar com a máquina.

Além disso, outro aspecto a ser considerado, talvez o mais importante deles, na reflexão ética sobre o uso indiscriminado da inteligência artificial, seja a política. Atualmente, duas grandes potências mundiais, Estados Unidos e China, têm travado uma espécie de guerra fria no que tange à tecnologia ${ }^{13}$. Daí se observa a questão política na sua predominância ou preponderância, quando o uso da tecnologia deva ser o resultado de uma boa relação entre sociedades distintas. Como explica Foucault (2008, p. 04), “(...) a maneira como se estabeleceu o domínio da prática do governo, seus diferentes objetos, suas regras gerais, seus objetivos de conjunto, a fim de governar da melhor maneira possível. Em suma é, digamos, o estudo da racionalização da prática governamental no exercício da soberania política.”. Assim, pode-se entender por política a prática de governo ${ }^{14}$ que tende a gerar mais benefícios para a sociedade que administra.

Neste sentido, Andrew Feenberg (2015, p. 224) explica que as alterações trazidas pela tecnologia não seriam abomináveis, pois as mudanças alcançariam seus patamares de ruptura até recomeçar em um novo ciclo de estabilidade:

Como vimos, hoje em dia, essas interações tornaram-se rotineiras, e emergem frequentemente novos grupos, à medida que os "mundos" vão mudando em resposta à mudança tecnológica. Esta dinâmica global de mudança tecnológica fecha o círculo descrito no paradoxo da ação: o que passa acaba por voltar. E porque nós temos experiência e somos capazes de refletir sobre essa experiência, podemos alterar as nossas tecnologias, para nos salvaguardarmos e para apoiar as novas atividades que as viabilizam.

12 "Muchas de nuestras actividades diarias pueden ser descritas como un conjunto simple de reglas que repetimos sistemáticamente. Nos despertamos a cierta hora del día, nos lavamos los dientes, nos duchamos y partimos para el trabajo. Por supuesto que modificamos nuestra rutina, pero solo lo suficiente como para que sea de algún modo más ventajosa de algún modo: nos dan más tiempo en la cama, minimiza la distancia entre paradas o satisface a todos en casa. En cierto modo, estas rutinas diarias capturan lo que llamamos un algoritmo em el sentido que, para ambos casos (e.g., en la rutina y en el algoritmo) hay una repetición del mismo conjunto de acciones una y otra vez (...). Por esto, en mi opinión, la noción de algoritmo descansa en la idea de que es parte de un procedimiento sistemático, formal y finito.".

13 Disponível em: https://www.vanityfair.com/news/2019/05/trumps-cold-war-with-china-could-literally-break-theinternet?verso=true.

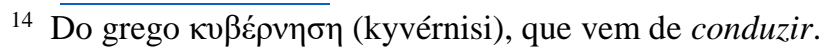

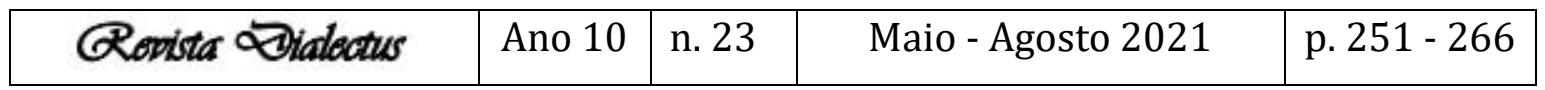


Por vezes o problema não é o dano feito pela tecnologia, mas sim o bem que poderia fazer se fosse reconfigurada para dar resposta a necessidades sem resposta.

As táticas ou estratégicas dos governos em cada época perseguem a manutenção dessa estrutura entre comandantes e comandados, e as novas ferramentas tecnológicas não são, senão, uma nova forma de empreender essa manutenção, que alcançou a forma mais sutil de perpetrar a atuação do governo. Nos termos explicitados por Foucault (2008, p. 32)

haveria, portanto, uma coisa que no regime de governo, na política governamental dos séculos XVI-XVII, já da Idade Média também, tinha constituído um dos objetos privilegiados da intervenção, da regulação governamental, uma coisa que havia sido o objeto privilegiado da vigilância e das intervenções do governo. E é esse lugar mesmo, e não a teoria econômica, que, a partir do século XVIII, vai se tornar um lugar e um mecanismo de formação de verdade. E, [em vez de] continuar a saturar esse lugar de formação da verdade com uma governamentalidade regulamentar indefinida, vai-se reconhecer - e é aí que as coisas acontecem - que se deve deixá-Io agir com a mínima possível de intervenções, justamente para que ele possa formular a sua verdade e propôla como regra e norma à prática governamental. Esse lugar de verdade não é, evidentemente, a cabeça dos economistas, mas o mercado.

Assim, o mercado controla o governo, assim como o governo controla, por diferentes meios, as vidas dos cidadãos que estão sob seu poder. Um bom exemplo a ser citado foi o escândalo do uso de dados de usuários de uma rede social para influenciar os votos dos cidadãos nas eleições presidenciais nos Estados Unidos em 2016. Naquela oportunidade, fora contratada a empresa Cambridge Analytica (CA), especializada em análise de dados para, através de um aplicativo (em forme de teste), recolher dados dos usuários que pudessem auxiliar no conhecimento de suas preferências. Assim, o algoritmo era capaz de aprender com as informações, que eram deliberadamente fornecidas pelos usuários por meio do aplicativo, e assim o algoritmo de inteligência artificial poderia detectar, além das preferências, predisposições à votação em determinado candidato. Com isso, a máquina "aprende" que pode minar os perfis que usaram o aplicativo com informações mais ou menos incisivas sobre o candidato que se desejava colocar no poder. $^{15}$ 15 Matéria completa disponível em https://www1.folha.uol.com.br/mercado/2018/03/entenda-o-escandalo-do-uso-de-
dados-do-facebook.shtml, https://brasil.elpais.com/brasil/2017/10/19/tecnologia/1508426945_013246.html, do jornal El País. Acessos em 12 de julho de 2019, às 15 horas e 43 minutos.

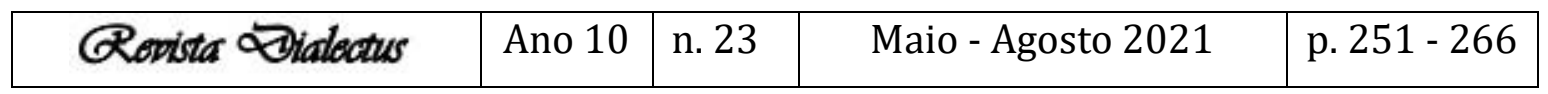


O poder está atrelado à questão do acúmulo de riquezas, quanto maior o capital, maior a possibilidade de se efetuarem trocas e que estas trocas tenham como fim "obter mais para si e menos para o outro". A lógica da biopolítica se observa do engendramento de estratégias para manter essa dinâmica de poder pautada pelo acúmulo de bens, o que foi estudado por Marx e Debord, mas que também se encontra na análise feita por Foucault (2008, p. 26):

a análise da biopolítica só poderá ser feita quando se compreender o regime geral dessa razão governamental de que lhes falo, esse regime geral que podemos chamar de questão de verdade - antes de mais nada da verdade econômica no interior cia razão governamental-, e, por conseguinte, se se compreender bem o que está em causa nesse regime que e o liberalismo, o qual se opõe à razão de Estado, ou antes, [a] modifica fundamentalmente sem talvez questionar seus fundamentos. Só depois que soubermos o que era esse regime governamental chamado liberalismo e que poderemos, parece-me, apreender o que é a biopolítica.

O uso de inteligência artificial, tendo em conta seu aprendizado com dados, funciona da seguinte forma: Quando se procura por imóveis numa ferramenta de busca como o Google, por exemplo, imediatamente toda a sorte de publicidade de imóveis - ao menos das empresas que pagam mais para ter a referida publicidade em evidência - é direcionada ao usuário. Nas redes sociais, como explicado anteriormente, as postagens com maior relevância possuem relação com o que mais procuramos ou vimos nas redes. E se o que mais vimos tem influência de quem paga mais para ser visto, é correto concluir que boa parte dos usuários estará imersa num círculo que oferece o que deve ser visto para influenciar e fomentar o desejo de buscas semelhantes.

Essa é a retroalimentação de que falamos anteriormente e se ela coordena o espetáculo que se tornou o mundo virtual, de modo que não é demasiado concluir que a inteligência artificial é usada como espécie de ferramenta biopolítica. A biopolítica foi um termo cunhado por Foucault e que se refere às formas de exercício de poder por meio de diferentes (ou novas) estratégias políticas, e neste sentido, remete ao que os governos realizam para manutenção de seu poder. Bruno Andreotti (2011, p. 60), citando e explicando Foucault, refere que

O conceito passa a se ocupar não somente dos indivíduos por meio de certos procedimentos disciplinares, mas também o conjunto dos viventes constituídos em uma determinada população. O que Foucault chamou de biopolítica era a gestão da saúde, da higiene, alimentação, sexualidade, natalidade, etc. na medida em se tornaram preocupações políticas, historicamente situadas no quadro de racionalidade política liberal (REVEL, 2005) É no percurso de seus estudos sobre governamentalização que o conceito aparece em sua obra. Para Foucault a governamentalização do Estado diz sobre uma

\begin{tabular}{|l|l|l|l|l|}
\hline Revista Dialectus & Ano 10 & n. 23 & Maio - Agosto 2021 & p. 251 - 266 \\
\hline
\end{tabular}


mudança na economia do poder: não mais o Estado de justiça medieval, nascido numa territorialidade feudal, marcado por um jogo de compromissos e litígios; não mais o Estado administrativo, nascido numa territorialidade de fronteira, com seus regulamentos e disciplinas, mas um Estado de governo, que não é definido essencialmente por sua territorialidade, mas por uma massa: a massa da população. A governamentalização desse "novo" Estado tem a população como objeto, utiliza a instrumentação do saber econômico numa sociedade controlada pelos dispositivos de segurança. (FOUCAULT, 2008a, p.144)

E conforme temos exposto exaustivamente, a questão do governo, do Estado, da própria política é saber qual o seu objeto, e este, nas palavras de Foucault (2008, p. 124), é a manutenção do capitalismo:

O objeto dessa discussão, e evidentemente um objeto político. E esse objeto político é o que? Pois bem, é muito simples. Simplesmente o problema da sobrevivência do capitalismo, da possibilidade e do campo de possibilidades que ainda se abre ao capitalismo. De fato, porque, se admitirmos - digamos assim, numa perspectiva marxista no sentido bem amplo do termo - que o que é determinante na história do capitalismo é a lógica econômica do capital e da sua acumulação, vocês hão de compreender que na verdade há um só capitalismo, já que há uma só lógica do capital. Ha um só capitalismo, um capitalismo que é definido, precisamente, pela lógica única e necessária da sua economia, e em relação ao a esse capitalismo pode-se apenas dizer que esta institui $(. . .)^{16}$.

\section{CONSIDERAÇÕES FINAIS}

A substituição do humano pelas máquinas inteligentes é algo concreto que se instala progressivamente. Não falamos, na presente pesquisa, de máquinas como as apresentadas nos filmes ou livros de ficção, que tomam suas próprias direções oposição aos seus criadores, mas sim as máquinas sendo utilizadas, paulatinamente nas diversas atividades humanas, deixando a maioria dos seres à margem do sistema em que a inteligência artificial foi inserida.

Nem todas as pessoas estiveram, estão ou estarão aptas a lidar com a programação das máquinas e isso nem poderia ser exigível. Cada ser humano nasce dotado de determinadas habilidades em certas áreas do conhecimento. As funções exercidas pelos indivíduos são plúrimas,

16 Homo oeconomicus. Parte-se sempre de uma questão econômica. "O homo oeconomicus que se quer reconstruir não é o homem da troca, não é o homem consumidor, é o homem da empresa e da produção. Estamos, aqui, num ponto importante sobre o qual procurarei tornar um pouco da próxima vez. Converge nele toda uma série de coisas.". (FOUCAULT, 2008, p. 111) e "o homo oeconomicus é aquele que é eminentemente governável. De parceiro intangível do laissez-faire, o homo oeconomicus aparece agora como o correlativo de uma governamentalidade que vai agir sobre o meio e modificar sistematicamente as variáveis do meio." (2008, p. 195 do e-book e 369 do livro impresso).

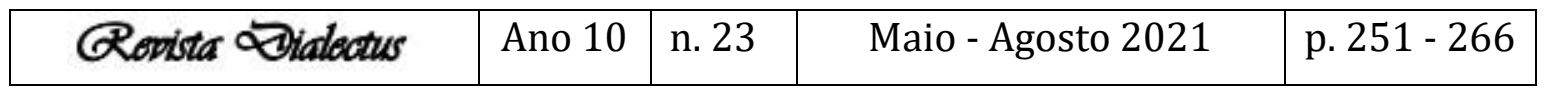


não se restringindo aos meros ditames do mercado, como ocorre no sistema capitalista, para cujas pretensões de grandes grupos os indivíduos são vistos como meras mercadorias.

Assim como a tecnologia da inteligência artificial representa uma grande conquista e pode contribuir para a solução de alguns dos problemas sociais e humanos, também serve a muitos interesses e pode potencializar os efeitos nocivos de alguns dos problemas discutidos ao longo do artigo. Explica-se: Como visto ao longo desta pesquisa, são ene situações de uso dos softwares de inteligência artificial que demonstram que o quesito da produtividade, próprio do contexto mercadológico, é o fím que o ser humano parece ter se imposto.

Apesar da complexidade das relações sociais movidas pelas dificuldades que se encontram nos diferentes grupos, especialmente no campo da moral, em que cada cultura parece ter desenvolvido conceitos diferentes do que é aceitável ou bom, alcançamos o atual estágio em que se o progresso é visado para a manutenção de sistemas de poder e o acúmulo de riquezas, também talvez seja possível um diálogo que efetivamente possa fazer das máquinas inteligentes aliadas e auxiliadoras, não potencializadoras de nossos vícios ou otimizadora de resultados exclusivamente econômicos.

O aprendizado dos algoritmos é orientado conforme as preferências dos usuários e estas, por sua vez, são determinadas pela influência do mercado. Resulta daí que as preferências dos indivíduos em diversos setores informam a máquina, assim como a máquina devolve resultados com base nessas informações, porém em conjunto com os interesses do mercado, orientando a certos comportamentos e tendências. Essa orientação influência nas escolhas dos indivíduos.

Pela investigação das consequências dos usos da tecnologia, associadas as suas possibilidades de aplicação e disseminação percebe-se a necessidade de discutir os impactos e as intencionalidades de suas aplicações. O uso da tecnologia na realidade contemporânea se dá em larga escala e afeta de modo geral todo o conjunto social. As mudanças nas relações e as possibilidades de atuação dos sujeitos são mais do que influenciadas, reestruturadas a partir do implemento da tecnologia. Essas mudanças aconteceram e continuam a acontecer em velocidades vertiginosas e não há como acompanhar os resultados, nem prever as consequências delas a priori, por se referirem a novos nichos de atuação e intervenção humanos. Como consequência mediata, o uso indiscriminado da inteligência artificial leva à paulatina perda de autonomia, ao menos para

\begin{tabular}{|l|l|l|l|l|}
\hline Qevista Dialectus & Ano 10 & n. 23 & Maio - Agosto 2021 & p. 251 - 266 \\
\hline
\end{tabular}


a grande maioria dos indivíduos, que são capturados por sistemas ou relações de poder. Ou seja, que são conduzidos a submissão a uma forma de inteligência organizada em nome da qualificação das relações e das condições produtivas.

Cabe uma investigação minuciosa orientada pela ética, para poder discutir as aplicações da tecnologia de modo consciente e responsável. O que se faz necessário, portanto, é discutir uma qualificação da programação para as máquinas inteligentes, considerando uma perspectiva ética. Esta perspectiva deverá considerar por um lado o alerta de Feenberg para que não sejamos objetificados na reorganização do mundo social pela perspectiva da tecnologia como uma nova organização cultural que determina nossos modos de existir e de se relacionar. E por outro lado com o cuidado de não ser capturados pelos processos de padronização e dessubjetivação, denunciados a partir da obra de Foucault, que podem ser identificados na formatação dos algoritmos, sobremaneira nos seus processos de filtragem das informações para atendimento das demandas mercadológicas. A aplicação de princípios éticos às programações das máquinas inteligentes, poderá conduzir a resultados comprometidos com o desenvolvimento e a salvaguarda humanos. Não se trata de questionar a automação, a utilização das máquinas e a implementação tecnológica, mas sim de buscar sua aplicação balizada pela ética com vistas ao desenvolvimento sustentável, em que o uso das máquinas possa ser discriminado, ou seja, razoavelmente claro e controlável, considerando o apreço à vida humana e, escalonadamente, extensível à salvaguarda de outros seres.

\section{REFERÊNCIAS}

ANDREOTTI, Bruno. Biopoder, biopolítica e multidão: Uma análise do desdobramento conceitual de Foucault em Antônio Negri. REU, Sorocaba, SP, v. 37, n. 2, p. 59-79, dez. 2011.

CAMILO, Juliana Aparecida de Oliveira e FURTADO, Rafael Nogueira. O conceito de biopoder no pensamento de Michel Foucault. Revista Subjetividades, vol.16 n. 3 - Fortaleza / Dezembro de 2016. Disponível em http://pepsic.bvsalud.org/scielo.php?script=sci_arttext\&pid=S2359$\underline{07692016000300003 .}$.

CASSIANO, Jeferson Martins. Fazer produzir e deixar consumar: as tecnologias de poder em Michel Foucault. Ipseitas, São Carlos, 2016, vol. 2, n. 2, p. 154-177.

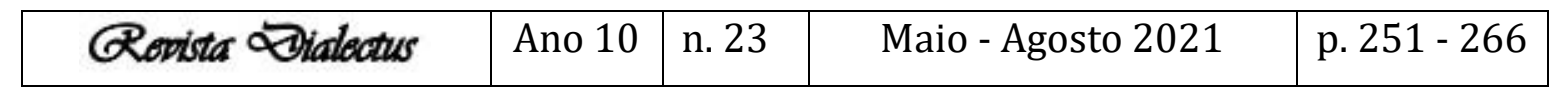


DEBORD, Guy. A sociedade do espetáculo. Rio de Janeiro: Contraponto, 1997. 238 p.

DOMINGOS, Pedro. O algoritmo mestre. São Paulo: Novatec Editora, 2017.

DURÁN, Juan Manuel. Ciencia de la computación y filosofía. Epistemology and Logic Research Group, Federal University of Santa Catarina (UFSC), Brazil, 2018. 227 p. Disponível em : https://www.researchgate.net/publication/330642140_Ciencia_de_la_computacion_y_filosofia_unidade s_de_analisis_del_software

FEENBERG, Andrew. Tecnologia, modernidade e democracia. Org. e Trad. Eduardo Boeira. $\begin{array}{llllll}\text { MIT } & \text { Portugal, } & 2015 . & 233 & \text { p. } & \text { Disponível }\end{array}$ https://www.sfu.ca/ andrewf/TECNOLOGIA_MODERNIDADE_DEMOCRACIA.pdf.

Ciencia, tecnología y democracia: distinciones y conexiones. Revista LatinoAmericana de Filosofia e História da Ciência. São Paulo, v. 7, n. 1, março de 2009. 184 p.

FEENBERG, Andrew. A teoria crítica de Andrew Feenberg: racionalização democrática, poder e tecnologia. Org. e Trad. Ricardo T. Neder. Brasília: Observatório do Movimento pela Tecnologia Social na América Latina/CDS/UNB/Capes, 2010.

FRANSSEN, Maarten, LOKHORST, Gert-Jan and VAN DE POEL, Ibo. Philosophy of Technology. The Stanford Encyclopedia of Philosophy (Fall 2018 Edition), Edward N. Zalta (ed.), 265 forthcoming. https://plato.stanford.edu/archives/fall2018/entries/technology/.

FOUCAULT, Michel. Microfísica do poder. 4a ed. Rio de Janeiro: Edições Graal, 1984. . Nascimento da biopolítica. São Paulo: Martins Fontes, 2008.

LUGER, George F. Inteligência Artificial. Estruturas e estratégias para a solução de problemas complexos. $4^{\mathrm{a}}$ ed. Porto Alegre: Boookmann, 2004. 774 p.

MACCARTHY, Jonh. The philosophy of AI and the AI of philosophy. Stanford University Computer Science Department. 2006. Disponível em http://jmc.stanford.edu/articles/aiphil2.html.

. Some philosophical problems from the standpoint of artificial intelligence. Computer Science Department, 1969. Disponível em http://wwwformal.stanford.edu/jmc/mcchay69.ps.

MACKENZIE, Adrian. Machine learners: archaeology of a data practice. Cambridge, MA: The MIT Press, 2017. 267 p.

\begin{tabular}{|l|l|l|l|l|}
\hline Revista Dialectus & Ano 10 & n. 23 & Maio - Agosto 2021 & p. 251 - 266 \\
\hline
\end{tabular}


MARX, Karl. O capital.

Disponível em https://www.marxists.org/portugues/marx/1867/ocapital-v1/index.htm. Versão HTML por José Braz, 2005.

MITCHELL, Tom Michael. Machine Learning. United States: McGraw-Hill International Editions, 1997, 413 p.

NOVAES, Henrique; DAGNINO, Renato. The fetish of technology. Revista ORE \& DEMO (Marília), v.5, n.2, p. 189-210, 2004.

O’NEIL, Cathy. Weapons of math destruction: how big data increases inequality and threatens democracy. New York: Crown Publishers, 2016. Disponível em https://we.riseup.net/assets/404114/Weapons+of+Math+Destruction+Cathy+O\%27Neil.pdf. 